\title{
Cascade H-Bridge Multilevel Inverter Fed Induction Motor Drive
}

\author{
Prarthana Nagle $^{1}$, C.S. Sharma ${ }^{2}$, Manoj Hirani ${ }^{3}$, S. Phulambrikar ${ }^{4}$ \\ Research Scholar, Department of Electrical Engineering, SATI, Vidisha (MP) ${ }^{1}$ \\ Associate Professor, Department of Electrical Engineering in SATI, Vidisha (MP) ${ }^{2,4}$ \\ Assistant Professor, Department of Electrical Engineering in SATI, Vidisha (MP) ${ }^{3}$
}

\begin{abstract}
Here in the proposed work the main focus is done on FFT analysis of output voltage of cascade H-bridge multilevel inverter employing selective harmonic elimination method. In selective harmonic elimination, a particular order of harmonic is selected and based on it, width of pulse is decided so that output voltage will be free from that harmonic[1]. Also focus is done on improving the efficiency of the multilevel inverter and quality of output voltage waveform. Selective Harmonics Elimination method is used to reduce the Total Harmonics Distortion (THD) value and to eliminate the lower order harmonics[2]. This topology is suitable for any number of levels. It reduces cost and complexity hence it is opt for industrial applications. In this paper fifth and seventh harmonics have been eliminated. Simulation work is done using the MATLAB software and experimental results have been presented to validate the theory.
\end{abstract}

Keywords: CHBMLI, SHE, Induction Motor.

\section{INTRODUCTION}

Multilevel inverters are DC to AC power conversion systems composed of an array of power semiconductors and capacitive voltage sources that, when properly connected and controlled[3], can generate a multi-step voltage waveform with variable and controlled frequency, phase and amplitude. The stepped waveform is synthesized by selecting different voltage levels generated by the proper connection of the load to the different capacitive voltage sources. This connection is performed by the proper switching of the power semiconductors [4]. The number of levels of inverter can be defined as the number of steps or constant voltage values that can be generated by the inverter between the output terminal and any arbitrary internal reference node within the converter.

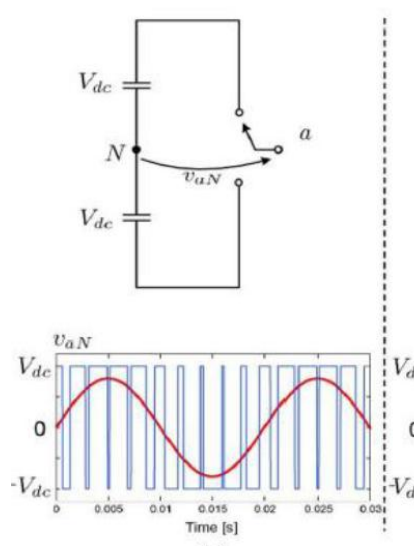

(a) (b)

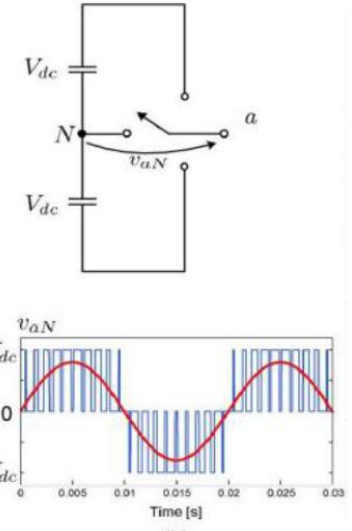

Fig 1 Output voltage waveform of (a) two-level inverter (b) three-level inverter
Typically, it is a dc-link node, and it is usually denoted by ' $N$ ' called neutral. To be called a multilevel inverter, each phase of inverter has to generate at least three different voltage levels. This differentiates the classical two-level voltage source inverter ( $2 \mathrm{~L}-\mathrm{VSC}$ ) from the multilevel inverter family. The concept showing the difference in Waveform and circuit diagram between two-level and three-level inverter are shown in figure below

It is worth mentioned that, generally different voltage levels are equidistant from each other in multiples of $\mathrm{V}_{\mathrm{dc}[5]}$.

There are many ways to combine power semiconductors and capacitive DC sources to generate multilevel output voltages. However, only some of them have become important from a practical point of view, and these are analyzed in the following section.

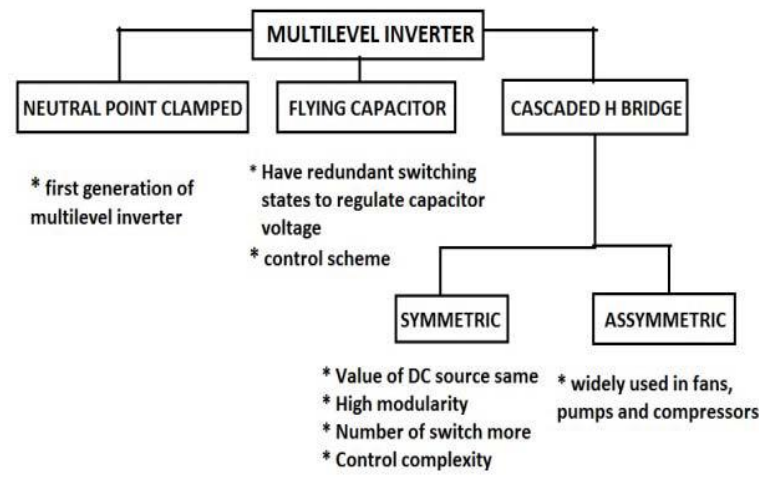

Fig 2: Types of multilevel inverter 
ISO 3297:2007 Certified

Vol. 5, Issue 1, January 2017

The development of multilevel inverters over the last decades has matured into three widely accepted topologies:

1) Neutral-point clamped (NPC) or diode clamped (DC),

2) Flying capacitor (FC)

3) Cascade H-bridge inverter

In the proposed work, only Cascade $\mathrm{H}$-bridge multilevel inverter is described in detail.

\section{CASCADE H-BRIDGE MLI TOPOLOGY}

A cascaded type multilevel inverter consists of series connection of full $\mathrm{H}$-bridge inverter units. The general function of this multilevel inverter is to synthesize desired ac output voltage from several Separate DC Sources (SDCS), which may be obtained from batteries, fuel cells or solar cells. The ac output voltage obtained from MLI is in the form of steps so here steps are specified in term of levels. In m-level MLI of cascade bridge type, (m-1)/2 units of full $\mathrm{H}$-bridge inverters are required for each single phase unit[6].

Here $\mathrm{m}=$ number of levels in phase to ground ac output voltage of multilevel inverter.

Each full bridge inverter requires one dc source and four IGBTs with feedback diodes. So for five levels, two units of full bridge inverters are required, with total number of eight switches per phase.

In this inverter topology all the switches are switched at fundamental frequency which causes low switching losses due to which it shows more reliability and feasibility. Fig 3 shows the structure of a three-level cascaded inverter with SDCS. Each SDCS is connected to an H-bridge inverter[7].

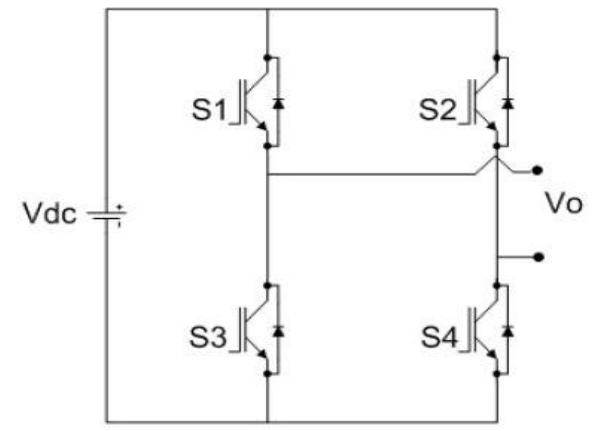

FIG:3 Three-Level cascade H-Bridge MLI

Table1: switching pattern of CHB MLI

\begin{tabular}{|l|l|l|l|l|}
\hline \multirow{2}{*}{$\begin{array}{l}\text { Output } \\
\text { Voltage } \\
V_{0}=V_{A N}\end{array}$} & \multicolumn{4}{|l|}{ Switch states } \\
\cline { 2 - 5 } & $S_{1}$ & $S_{2}$ & $S_{3}$ & $S_{4}$ \\
\hline$V_{d c}$ & 1 & 0 & 0 & 1 \\
\hline \multirow{2}{*}{0} & 1 & 1 & 0 & 0 \\
\cline { 2 - 5 } & 0 & 0 & 1 & 1 \\
\hline$-V_{d c}$ & 0 & 1 & 1 & 0 \\
\hline
\end{tabular}

The output terminals of various full bridge inverters are connected in series to make stepped AC output voltage. Unlike the diode-clamped or flying capacitors inverter, the cascaded inverter does not require any voltage-clamping diodes or voltage-balancing capacitors.

\section{PROPOSED METHODOLOGY}

Selective harmonic elimination (SHE) in cascade Hbridge multilevel inverter:

In selective harmonic elimination method, there are some particular order of harmonics of output voltage of MLI are selected, according to the order of harmonics the correct instant of switching of any switch of particular single phase full bridge inverter is decided by following equations[8].

For eliminating $5^{\text {th }}$ and $7^{\text {th }}$ order harmonics from sevenlevel inverter, which employ three full bridge inverters,

$$
\begin{gathered}
\cos \alpha+\cos \beta+\cos \Upsilon=0.8 * 3 \\
\cos 5 \alpha+\cos 5 \beta+\cos 5 \Upsilon=0 \\
\cos 7 \alpha+\cos 7 \beta+\cos 7 \Upsilon=0
\end{gathered}
$$

Here $\alpha<90, \quad \beta<90, \quad \Upsilon<90$,

By some iteration in MATLAB, the switching angles for 7-level cascaded H-bridge multilevel inverter are calculated.

$$
\alpha=11.5^{\circ}, \quad \beta=28.71^{\circ}, \quad \Upsilon=57.1^{\circ}
$$

However if we require to change the magnitude and frequency of output voltage of MLI employing SHE[9], then magnitude of output voltage cannot be changed, because width of pulse is fixed as per the elimination of particular order of harmonic using SHE. The frequency of output voltage can be changed by varying explicit period.

\section{SIMULATIONS AND RESULT}

The simulation if three phase seven level cascade H-bridge MLI fed induction motor was done using matlab.

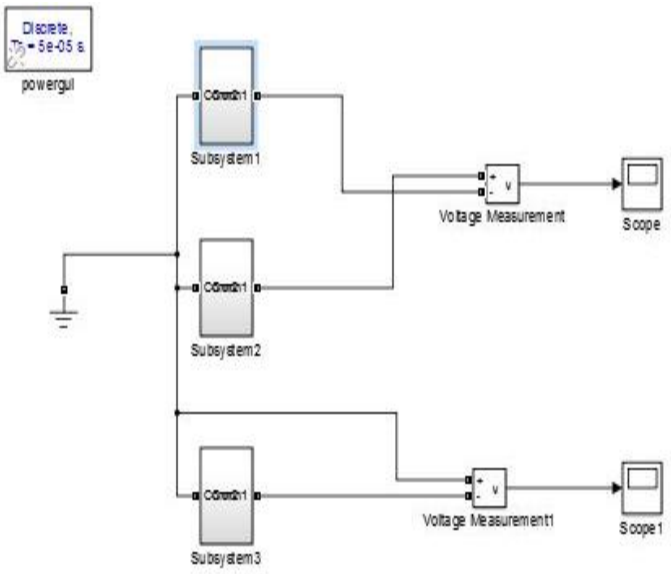

Fig 4: Simulation diagram for seven-level inverter 
IJIREEICE

International Journal of Innovative Research in Electrical, Electronics, Instrumentation and Control Engineering

ISO 3297:2007 Certified

Vol. 5, Issue 1, January 2017

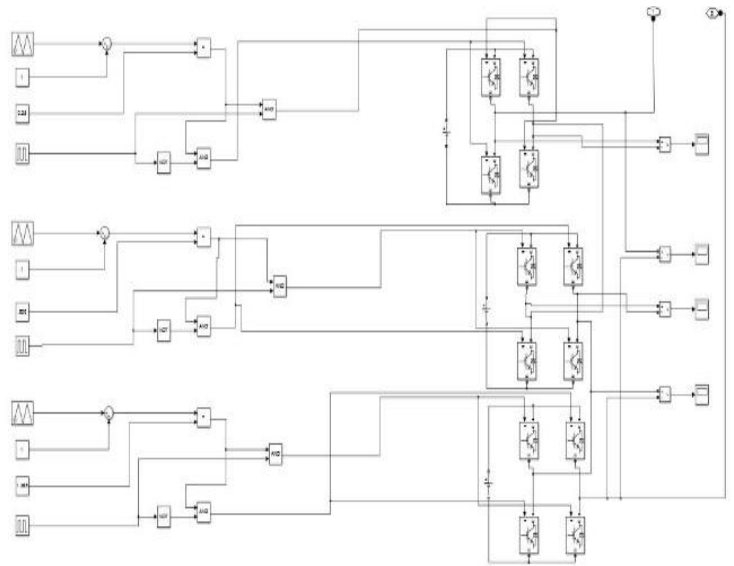

Fig 5: Control strategy for phase A of seven-level inverter

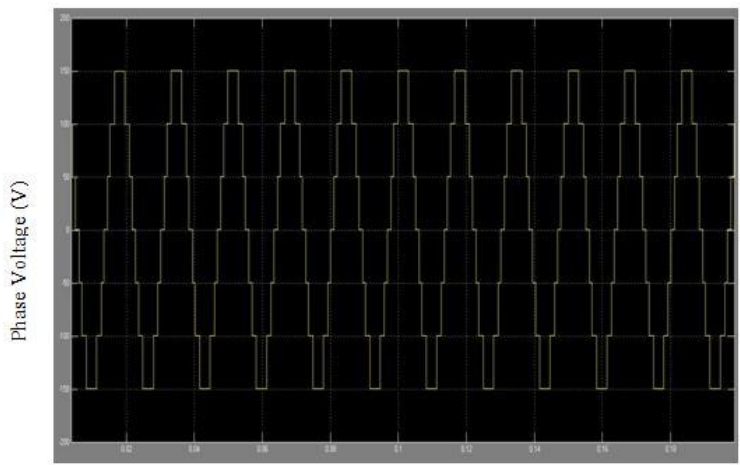

Time in second

Fig 6 Output phase to neutral voltage waveform of sevenlevel inverter

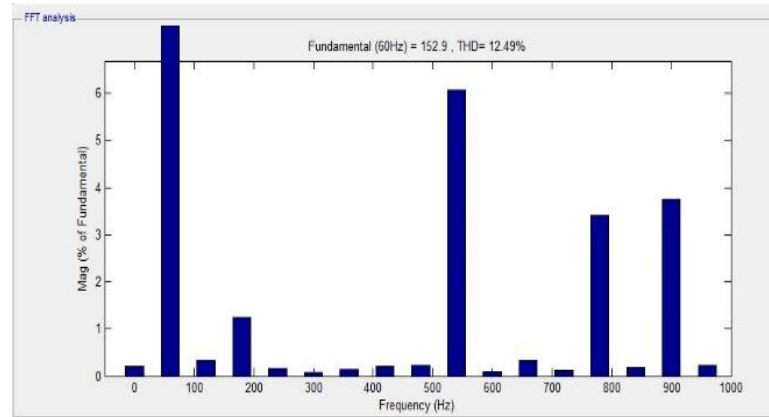

Fig 7 FFT analysis of phase to neutral voltage waveform of seven-level inverter

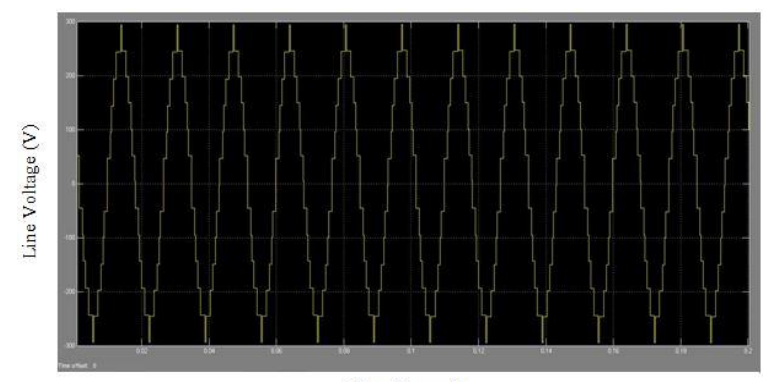

Time (Second)

Fig 8 Output line-line voltage waveform of seven-level inverter

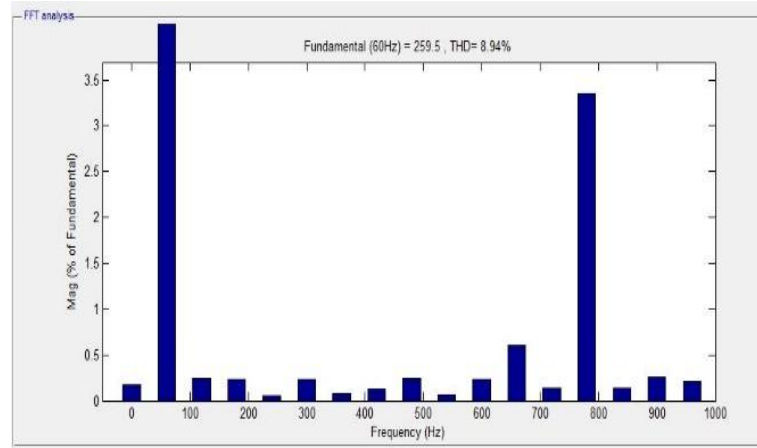

Fig 9 FFT analysis of line to line voltage waveform of seven-level inverter

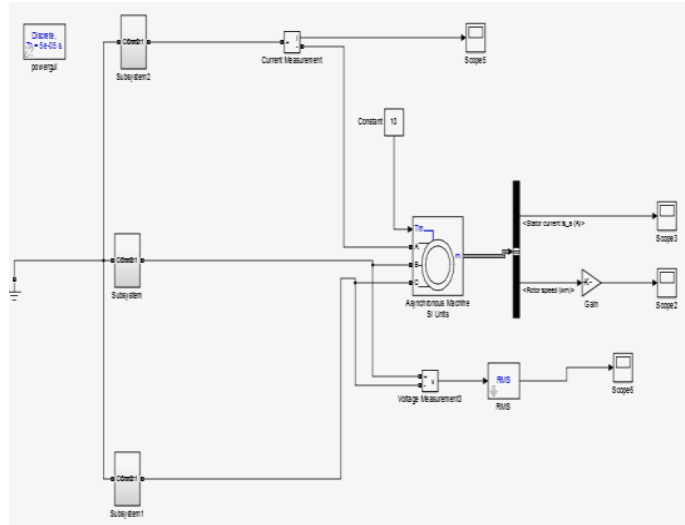

Fig 10: Simulation diagram for seven-level inverter fed induction motor drive

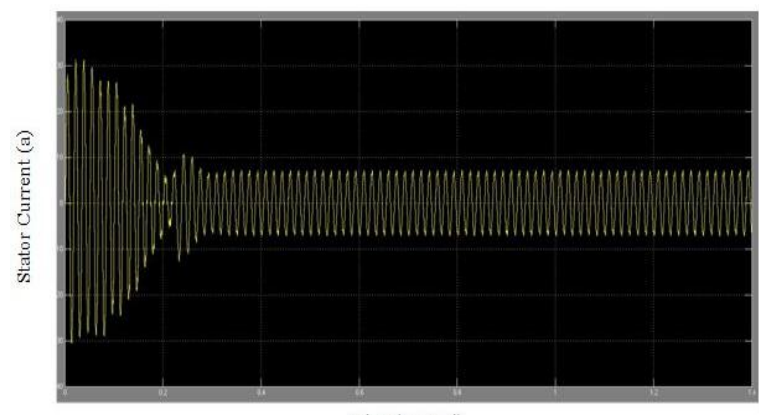

Time(Second)

Fig 11 waveform of stator current of three phase induction motor

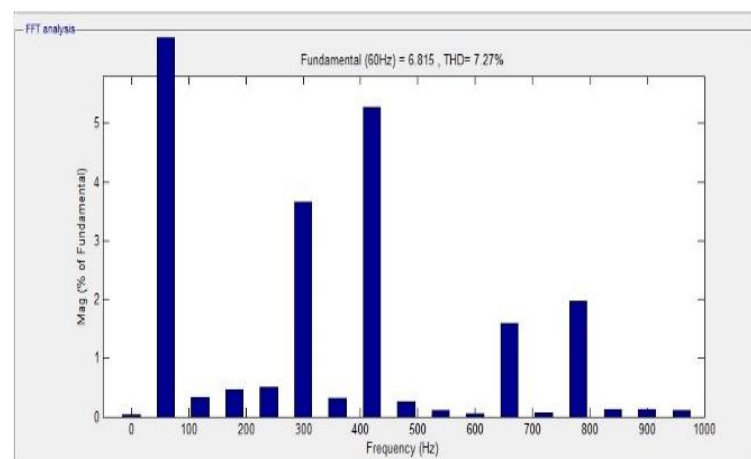

Fig 12 FFT analysis of stator current of three phase induction motor 


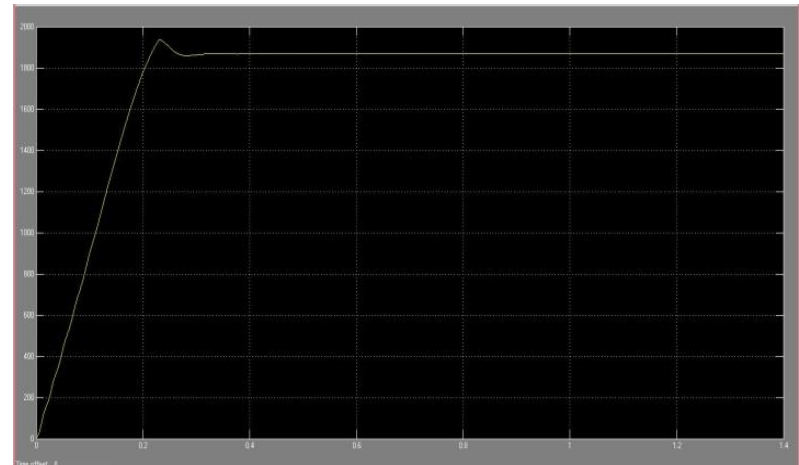

Fig 13 Waveform of rotor speed of induction motor

\section{CONCLUSION}

In FFT analysis of multi-level inverter, the control strategy for all the switches is made by using Matlab. In this method, pulse width of output voltage of full bridge inverter is decided by the order of harmonic, which has to be removed from output voltage of MLI. So here magnitude of output voltage can only be controlled by external circuitry. In the proposed scheme THD of lineline voltage of $8.94 \%$ can be obtained. A generalized control strategy is made by using Matlab with the help of which multi-level inverter of any level can be made.

\section{REFERENCES}

[1] A. Maheswari and I. Gnanambal," Low Order Harmonic Reduction of Three Phase Multilevel Inverter",J SciIndRes,Vol. 73, March 2014, pp. 168-172.

[2] damoun ahmadi, kezou, cong li, yi huang and jin wang, "a universal selective harmonic elimination method for high-power inverters", ieee transactions on power electronics, vol. 26, no. 10,pp2743-2752,2011

[3] jose roriguez, jih-sheng, and fang zheng peng, "multilevel inverter: a survey of topologies, controls, and applications," ieee transactions on industrial electronics, vol. 49, no. 4, pp. 724-738august 2002.

[4] E. Guan, P. Song, M. Ye, and B. Wu, "Selective Harmonic Elimination Techniques for Multilevel Cascaded H-Bridge Inverters",Kuala Lumpur, Malaysia, pp. 1441-1446, 28 November1 December 2005.

[5] Malinowski M, Gopakumar K, Jose Rodriguez \& Marcelo A Perez, A survey on Cascaded Multilevel inverters, IEEE Trans Ind Elect, 57 (2010) $2197-2206$

[6] Tolbert L M, Peng F Z \&Habetler T G, Multilevel converters for large electric drives, IEEE Trans IndAppl, 35 (1999) 36-44.

[7] A. Maheswari and I. Gnanambal, "Harmonic Analysis of Cascaded H-bridge Seven Level Inverter for RL Load Applications", Asian Power Electronics Journal,Vol. 6, No. 2, pp 13-18, Dec 2012. Manjrekar M D

[8] A. Maheswari and I. Gnanambal, "Harmonic Analysis of Cascaded H-bridge Seven Level Inverter",Asian Power Electronics Journal,Vol. 6, No. 2, pp 13-18, Dec 2012.

[9] A. Maheswari, S.Mahendran and I. Gnanambal, "Implementation of Fundamental Frequency Switching Scheme on Multi -Level Cascaded H- Bridge Inverter Fed Three Phase Induction Motor Drive”, Wulfenia Journal,Vol 19, No. 8, pp.10-23, Aug 2012. 